\title{
KOMPETENSI SOSIAL GURU IPA DI MADRASAH IBTIDAIYAH SWASTA ANNUR ISLAMIC FULLDAY SCHOOL TAHUN AJARAN 2020-2021
}

\author{
Ranisa Sagita ${ }^{1}$, Nazar Ikhwan², Rohanis Luthfiyyah Rahma ${ }^{3}$, Luthfi Hakim ${ }^{4}$ \\ 1,2,3,4 Pendidikan Guru Madrasah Ibtidaiyah, Universitas Islam Negeri Sumatera Utara Medan \\ Jl. William Iskandar Ps. V, Medan Estate, Kec. Percut Sei Tuan, Deli Serdang, 20371 \\ ${ }^{1}$ Email: ranisasagita1@gmail.com \\ ${ }^{2}$ Email: ikhwannazar0337@gmail.com \\ ${ }^{3}$ Email: ach38418@gmail.com \\ ${ }^{4}$ Email: qoriluthfihakim150902@gmail.com
}

\begin{abstract}
ABSTRAK
Kompetensi sosial adalah kemampuan guru untuk berkomunikasi dan berinteraksi secara efektif dan efisien dengan peserta didik, sesama guru, orangtua/ wali peserta didik dan masyarakat sekitar. Seorang guru harus berusaha mengembangkan komunikasinya baik dilingkungan sekolah maupun di lingkungan masyarakat. Penelitian ini menggunakan penelitian jenis Kualitatif naturalistik, yang bertujuan untuk membuat pecandraan secara sistematis, akurat mengenai fakta-fakta yang terjadi atau ditemui dilapangan. Hasil dari penelitian ini adalah bahwa Guru IPA belum sepenuhnya menerapakan indikator kompetensi sosial. Adapun indikator yang belum terlaksana sepenuhnya yakni membangun komunikasi secara efektif terhadap orangtua siswa, serta guru IPA belum berkomunikasi dengan komunitas profesi sendiri dan profesi lain secara lisan dan tulisan atau bentuk lain.
\end{abstract}

Kata Kunci: Kompetensi Sosial Guru, Guru IPA, Kompetensi Sosial Guru IPA.

\section{(i) (2)}

This work is licensed under a Creative Commons Attribution-ShareAlike 4.0 CC BY-SA International License.

\begin{abstract}
Social competence is the ability of teachers to communicate and interact effectively and efficiently with students, fellow teachers, parents/guardians of students and the surrounding community. A teacher must try to develop communication both in the school environment and in the community. This research uses naturalistic qualitative research, which aims to make jokes in a systematic, accurate and accurate way about the facts or encountered in the field. The result of this research is that science teachers have not fully implemented social competence indicators. The indicators that have not been fully implemented are building effective communication with parents of students, and science teachers have not communicated with their own professional community and other professions orally and in writing or in other forms.
\end{abstract}

Keywords: Teacher Social Competence, Science Teacher, Science Teacher Social Competence.

\section{PENDAHULUAN}

Pendidikan merupakan bagian yang perlu untuk senantiasa ditingkatkan kualitasnya. Hal ini tentunya dipengaruhi dari guru atau pendidik yang hadir dalam rangka meningkatkan kualitas pendidikan itu sendiri. Guru adalah sosok yang dinobatkan dengan semboyan "digugu dan ditiru". Hal ini mengisyaratkan bahwa guru adalah sosok yang semestinya menjadi pribadi 
yang baik untuk dicontoh dari masing-masing peserta didiknya dalam lingkungan sekolah, serta menjadi tauladan bagi masyarakat luas di lingkungan sosial.

Guru tentunya harus memiliki kompetensi, terlebih lagi mengembangkannya. Adapun dalam Undang-Undang Republik Indonesia Nomor 14 Tahun 2005 tentang Guru dan Dosen, dijelaskan bahwa kompetensi adalah seperangkat pengetahuan, keterampilan, dan perilaku yang harus dimiliki, dihayati, dan dikuasai oleh guru atau dosen dalam melaksanakan tugas keprofesionalan (Suhana, Nanang Hanafiah, \& Cucu, 2012).

Lebih lanjut, dalam Standar Nasional Pendidikan, penjelasan pasal 28 ayat (3) butir dikemukakan bahwa yang dimaksud dengan kompetensi sosial adalah kemampuan guru sebagai bagian dari masyarakat untuk berkomunikasi dan bergaul secara efektif dengan peserta didik, sesama pendidik, tenaga kependidikan, orangtua/ wali peserta didik, dan masyarakat sekitar. Mulyasa (Mulyasa, 2007) melanjutkan bahwa kompetensi sosial sekurang-kurangnya memiliki beberapa indikator berikut ini:

1. Berkomunikasi secara lisan, tulisan, dan isyarat.

2. Menggunakan teknologi komunikasi dan informasi secara fungsional.

3. Bergaul secara efektif dengan peserta didik, sesama pendidik, tenaga kependidikan, orangtua/ wali peserta didik.

4. Bergaul secara santun dengan masyarakat sekitar.

Bersamaan dengan itu, dalam Lampiran Permendiknas Nomor 16 Tahun 2007 (Luk Staff UGM, 2021) dapat terlihat pada tabel 1 berikut ini:

Tabel 1. Lampiran Permendiknas Nomor 16 Tahun 2007

\begin{tabular}{|c|c|c|}
\hline No. & Standar Kompetensi & Indikator \\
\hline 1 & $\begin{array}{l}\text { Bersikap inklusif, bertindak } \\
\text { objektif, serta tidak } \\
\text { diskriminatif karena } \\
\text { pertimbangan jenis kelamin, } \\
\text { agama, ras, kondisi fisik, latar } \\
\text { belakang keluarga, dan status } \\
\text { sosial ekonomi. }\end{array}$ & $\begin{array}{l}\text { 1.1. Bersikap inklusif dan objektif terhadap } \\
\text { peserta didik, teman sejawat dan } \\
\text { lingkungan sekitar dalam melaksanakan } \\
\text { pembelajaran. } \\
\text { 1.2. Tidak bersikap diskriminatif terhadap } \\
\text { peserta didik, teman sejawat, orang tua } \\
\text { peserta didik dan lingkungan sekolah } \\
\text { karena perbedaan agama, suku, jenis } \\
\text { kelamin, latar belakang keluarga, dan } \\
\text { status sosial-ekonomi. }\end{array}$ \\
\hline 2 & $\begin{array}{l}\text { Berkomunikasi secara efektif, } \\
\text { empatik, dan santun dengan } \\
\text { sesama pendidik, tenaga } \\
\text { kependidikan, orang tua, dan } \\
\text { masyarakat. }\end{array}$ & $\begin{array}{l}\text { 2.1. Berkomunikasi dengan teman sejawat } \\
\text { dan komunitas ilmiah lainnya secara } \\
\text { santun, empatik dan efektif. } \\
\text { 2.2. Berkomunikasi dengan orang tua peserta } \\
\text { didik dan masyarakat secara santun, } \\
\text { empatik, dan efektif tentang program }\end{array}$ \\
\hline
\end{tabular}


Beradaptasi di tempat bertugas di seluruh wilayah Republik Indonesia yang memiliki keragaman sosial budaya.

Berkomunikasi dengan komunitas profesi sendiri dan profesi lain secara lisan dan tulisan atau bentuk lain pembelajaran dan kemajuan peserta didik.

2.3. Mengikutsertakan orang tua peserta didik dan masyarakat dalam program pembelajaran dan dalam mengatasi kesulitan belajar peserta didik.

3.1. Beradaptasi dengan lingkungan tempat bekerja dalam rangka meningkatkan efektivitas sebagai pendidik.

3.2. Melaksanakan berbagai program dalam lingkungan kerja untuk mengembangkan dan meningkatkan kualitas pendidikan di daerah yang bersangkutan.

4.1. Berkomunikasi dengan teman sejawat, profesi ilmiah, dan komunitas ilmiah lainnya melalui berbagai media dalam rangka meningkatkan kualitas pembelajaran.

4.2. Mengkomunikasikan hasil-hasil inovasi pembelajaran kepada komunitas profesi sendiri secara lisan dan tulisan maupun bentuk lain.

Yang dimaksud dengan kompetensi sosial adalah kemampuan guru untuk berkomunikasi dan berinteraksi secara efektif dan efisien dengan peserta didik, sesama guru, orangtua/ wali peserta didik, dan masyarakat sekitar.

Lebih lanjut, Wibowo mengemukakan bahwa kompetensi sosial adalah kemampuan guru untuk berkomunikasi dan berinteraksi secara efektif dan efisien dengan peserta didik, sesama guru, orangtua/ wali peserta didik dan masyarakat sekitar. Seorang guru harus berusaha mengembangkan komunikasinya baik dilingkungan sekolah maupun di lingkungan masyarakat (Wibowo \& Hamrin, 2012).

Ilmu Pengetahuan Alam (IPA) merupakan ilmu yang berhubungan dengan cara mencari tahu tentang alam sekitar secara sistematis, sehingga IPA bukan hanya penguasaan kumpulan pengetahuan yang berupa fakta-fakta, konsep-konsep, atau prinsip-prinsip saja tetapi juga merupakan suatu proses penemuan (BSNP, 2006).

Menurut Yumarlin (Yumarlin, 2013) berpendapat bahwa mata pelajaran IPA menjadi wahana untuk peserta didik agar mampu mempelajari diri sendiri dan alam sekitar dan bisa menerapkannya di dalam kehidupan sehari-hari.

Pada umumnya, setiap ilmu pengetahuan tertentu memiliki tujuan masing-masing. Terkhusus pada mata pelajaran Ilmu Pengetahuan Alam (IPA), bertujuan untuk mengetahui tentang alam sekitar serta menemukan fakta-fakta yang bersifat ilmiah yang pada akhirnya berbentuk sikap menjaga, merawat, serta menghargai alam sekitar sebagai ciptaan Tuhan. 
Secara umum, fungsi mata pelajaran Ilmu Pengetahuan Alam (IPA) dapat terlihat pada bagian berikut ini:

1. Mengembangkan keterampilan memecahkan masalah

2. Mengenal dan meningkatkan rasa cinta dengan alam sekitar

3. Mengembangkan minat belajar ipa siswa

4. Mengembangkan konsep yang memiliki hubungan dengan kehidupan sehari-hari Sehingga dapat disimpulkan bahwa fungsi mata pelajaran IPA adalah mengembangkan keterampilan untuk memecahkan suatu masalah sehingga siswa mampu memahami dan meningkatkan tentang hubungan dengan kehidupan sehari-hari dengan ilmu pengetahuan alam.

Hasil observasi yang peneliti lakukan di MIS Annur Islamic Fullday School menerangkan bahwa guru IPA belum ditemukan berkomunikasi secara langsung dengna orangtua peserta didik. Terlebih lagi, guru IPA belum terlihat bertemu dengan tujuan tertentu dengan orangtua siswa secara kelompok.

Atas dasar dugaan di atas, maka peneliti merasa tertarik untuk melakukan penelitian dengan judul Kompetensi Sosial Guru IPA di Madrasah Ibtidaiyah Swasta Annur Islamic Fullday School Tahun Ajaran 2020-2021.

Adapun yang menjadi fokus dalam penelitian ini adalah sikap guru yang inklusif, bertindak objektif, serta tidak diskriminatif, sikap guru dalam berkomunikasi secara efektif, empatik, dan santun dengan sesama pendidik, tenaga kependidikan, orang tua, dan masyarakat, sikap guru dalam beradaptasi di tempat bertugas di seluruh wilayah Republik Indonesia yang memiliki keragaman sosial budaya, dan sikap guru dalam berkomunikasi dengan komunitas profesi sendiri dan profesi lain secara lisan dan tulisan atau bentuk lain.

Adapun yang menjadi tujuan dalam penelitian ini adalah sebagai berikut:

1. Untuk mengetahui sikap guru yang inklusif, bertindak objektif, serta tidak diskriminatif.

2. Untuk mengetahui sikap guru dalam berkomunikasi secara efektif, empatik, dan santun dengan sesama pendidik, tenaga kependidikan, orang tua, dan masyarakat.

3. Untuk mengetahui sikap guru dalam beradaptasi di tempat bertugas di seluruh wilayah Republik Indonesia yang memiliki keragaman sosial budaya.

4. Untuk mengetahui sikap guru dalam berkomunikasi dengan komunitas profesi sendiri dan profesi lain secara lisan dan tulisan atau bentuk lain.

\section{METODE PENELITIAN}

Metode penelitian atau metode ilmiah adalah prosedur atau langkah dalam mendapatkan pengetahuan ilmiah. Jadi, metode penelitian adalah cara sistematis untuk menyusun ilmu 
pengetahuan. Sedangkan tehnik penelitian adalah cara yang digunakan untuk melaksanakan metode penelitian itu sendiri. Metode penelitian biasanya mengacu pada bentuk-bentuk penelitian (Suryana, 2010).

Ali dan Yusof (Ali \& Yusof, 2011) mengatakan bahwa "Any investigation which does not make use of statistical procedures is called "qualitative" nowdays, as if this were a quality label in itself." Diartikan dalam bahasa Indonesia, sebagai berikut "Penyelidikan apa pun yang tidak menggunakan prosedur statistik sekarang disebut "kualitatif", seolah-olah ini adalah label kualitas itu sendiri."

Metode penelitian dalam hal ini menggunakan jenis Penelitian Kualitatif, dimana ini juga dikenal sebagai penelitian naturalistik, yang menggunakan lingkungan alamiah dan tidak dimanipulasi atau diatur sedemikian rupa (Hasyim, 2016).

Creswell (Creswell, 2007) menyebutkan bahwa terdapat beberapa karakteristik dalam penelitian jenis kualitatif yang baik, antara lain sebagai berikut:

1. Peneliti menggunakan prosedur mendapatkan data yang tepat.

2. Peneliti membatasi penelitian di dalam asumsi dan karakteristik dari pendekatan kualitatif.

3. Peneliti menggunakan pendekatan kualitatif dalam penelitiannya.

4. Peneliti memulai penelitian dengan satu fokus.

5. Penelitian berisi metode yang rinci, pendekatan yang tepat dalam pengumpulan data, analisis data, dan penulisan laporan.

6. Peneliti menganalisis data menggunakan pemisahan analisis dalam beberapa level.

7. Peneliti menulis secara persuasif, sehingga pembaca dapat merasakan pengalaman yang sama.

8. Proses penelitian dengan pendekatan kualitatif

Adapun sifat dari penelitian kualitatif itu sendiri yakni menuturkan pemecahan masalah yang ada di lokasi penelitian berdasarkan data-data temuan, menganalisis, dan menginterpretasikannnya. Selanjutnya, yang menjadi tujuan dalam penelitian kualitatif adalah membuat pecandraan secara sistematis, akurat mengenai fakta-fakta yang terjadi atau ditemui dilapangan (Suryabrata, 2013).

Penelitian ini dilangsungkan di Madrasah Ibtidaiyah Annur Islamic Fullday School, yang berlokasi di Jalan Arnan, Pelawi Utara, Babalan, Kabupaten Langkat, Sumatera Utara Kode Pos 20881. Lembaga ini menjalankan program kegiatan belajar mengajar dari pukul 07.30 wib hingga pada pukul 16.30 wib.

Peneliti terlebih dahulu datang ke lokasi penelitian, untuk melihat keadaan di sekolah MIS Annur Islamic Fullday School, khususnya guru IPA selama aktivitas kegiatan belajarnya 
di sekolah. Selanjutnya, peneliti melakukan observasi lapangan, untuk mengambil data yang ditemui saat observasi.

Setelah ditemukan beberapa data terkait dengan topik penelitian melalui observasi lapangan, maka selanjutnya peneliti menggunakan data yang ada dengan menerapkan triangulasi. Untuk itu, peneliti mulai melakukan validasi terhadap data yang diperoleh, dengan melakukan wawancara. Dalam hal ini, peneliti membagi informan menjadi dua bagian, yaitu informan primer dan informan sekunder. Informan primer dalam hal ini adalah guru Ilmu Pengetahuan Alam (IPA) di MIS Annur Islamic Fullday Shcool sendiri. Sedangkan informan sekunder, yakni Kepala Madrasah dan Guru (teman sejawad) yang ada di MIS Annur Islamic Fullday School.

Untuk mendapatkan keabsahan data, peneliti melakukan studi dokumen, dimana hal ini bertujuan untuk mencari kebenaran atau pendukung dari data yang didapatkan sebelumnya, yakni wawancara. Peneliti mengunjungi ruangan tata usaha, dimana disana merupakan tempat ditemukannya berbagai administratif atau dokumen terkait tentang fokus penelitian yang dilangsungkan.

\section{HASIL DAN PEMBAHASAN}

\section{A. Bersikap Inklusif, Bertindak Objektif, Serta Tidak Diskriminatif}

Sikap inklusif maksudnya adalah menginginkan kebersamaan meskipun mengakui adanya perbedaan. Peserta didik adalah manusia yang beragam, dengan kemampuan dan ciri tersendiri masing-masing diantara mereka. Oleh sebab itu, inklusif merupakan sikap yang semestinya dihadirkan bagi diri seorang guru, agar dapat mencapai tujuan pembelajaran yang diinginkan.

Hasil wawancara yang dilakukan terhadap Guru IPA, memberikan penjelasan bahwa sikap inklusif dan tidak diskriminatif sudah diterapkan di dalam kegiatan belajar mengajar. Guru IPA juga menuturkan bahwasanya kebersamaan adalah sesuatu yang penting agar dapat menstabilkan kondisi kelas, dan tidak saling jatuh menjatuhkan.

Dalam kegiatan pembelajaran, guru IPA membentuk kelompok dengan tanpa mempertimbangkan siswa yang pintar atau siswa yang belum pintar. Itu semua dilakukan dengan random, dengan harapan jauh lebih baik dan terhindar dari sikap diskriminatif.

Sejalan dengan itu, melalui wawancara dengan Kepala Sekolah, menyatakan bahwa lembaga tidak mendukung sikap diskriminatif, yang justru akan berdampak buruk bagi kelangsungan kegiatan belajar mengajar. Hal ini sebenarnya, menjadi sesuatu yang sangat dihindarkan semampu mungkin, karena dampaknya cukup buruk, bahkan bagi peserta didik itu sendiri. 


\section{B. Berkomunikasi Secara Efektif, Empatik, dan Santun dengan Sesama Pendidik, Tenaga Kependidikan, Orang Tua, dan Masyarakat}

Membangun komunikasi yang baik adalah hal yang dapat membantu meningkatkan kualitas diri bagi seorang pendidik. Komunikasi yang baik antar sesama pendidik, akan memungkinkan untuk terbukanya pemahaman akan hal-hal baru yang dapat membantu menyelesaikan permasalahan yang ditemui dalam kelas.

Hasil observasi yang dilakukan peneliti, memperlihatkan bahwa Guru IPA dapat berkomunikasi dengan baik, efektif, dan santun dengan guru yang ada di MIS Annur Islamic Fullday School. Hal ini diperlihatkan dengan sikap guru IPA saat berada dalam ruang guru, yang mampu membangun komunikasi dengan baik, dengan tutur kata yang sopan dengan guru lainnya.

Wawancara yang dilakukan dengan Kepala Sekolah, memberikan penjelasan bahwa guru IPA tidak tercatat dalam hal melanggar aturan sekolah yang berarti. Oleh karenanya, hubungan antara tenaga pendidik dengan Guru IPA masih tetap terjalin dengan baik hingga saat ini. Lebih lanjut, Kepala Sekolah juga mengungkapkan bahwa tutur kata dan sopan santun masih terlihat pada Guru IPA, yang membuatnya menjalin hubungan baik antar guru, dan tenaga kependidikan.

Disisi lain, Tenaga Kependidikan (Administrator) membenarkan hal ini. Dalam wawancara yang dilakukan, memberikan penjelasan bahwa guru IPA terkesan sopan saat berbicara dengan Tenaga Operator/ Administrator. Tatkala berhubungan untuk hal administratif, Guru IPA cenderung berkata lebih sopan dan santun, meski dengan usia yang tidak terpaut jauh berbeda.

Disisi lain, peneliti melakukan wawancara dengan salah satu orangtua siswa. Dalam hal ini memberikan penjelasan bahwasanya guru IPA terkesan jarang untuk membangun hubungan atau berkomunikasi dengan orangtua siswa. Lebih lanjut, orangtua siswa mengatakan bahwa tidak dibentuknya Grup Khusus di sosial media seperti WhatsApp Grup, yang dapat membangun komunikasi antara guru dan orangtua siswa.

Keadaan ini dibenarkan oleh Guru IPA, yang mengatakan bahwasanya belum membentuk Grup Khusus dalam sosial media untuk berhubungan dengan orangtua siswa. Meski demikian, tatkala mendapati persoalan yang perlu dibahas, guru IPA dapat menghubungi orangtua siswa secara langsung melalui panggilan telepon.

Dari hasil wawancara di atas, dapat diambil kesimpulan bahwa guru IPA telah menjalankan subindikator berkomunikasi secara efektif antar guru. Meski demikian, terdapat sisi dimana Guru IPA belum membangun komunikasi secara efektif dengan orangtua siswa. Ini 
diperlihatkan dengan belum dibuatnya tempat khusus dimana guru IPA dapat terhubung langsung dengan orangtua siswa secara kelompok, meski pada dasarnya guru IPA dapat berhubungan langsung melalui panggilan telepon dengna orangtua peserta didik, bilamana itu dibutuhkan.

\section{Beradaptasi di Tempat Bertugas}

Adaptasi di tempat bertugas adalah sesuatu yang tidak dapat diabaikan dan terlihat cukup penting. Hal ini tentunya untuk mendukung keberhasilan kegiatan belajar mengajar secara khusus, dan tujuan pendidikan secara umum.

Guru IPA mampu berbaur dengan sesama guru di MIS Annur Islamic Fullday School, dan membangun komunikasi yang baik antar guru disana. Hasil wawancara yang dilakukan dengan informan Guru IPA, memberikan penjelasan bahwasanya tidak memiliki masalah apapun dengan komunikasi antara guru di sekolah MIS Annur Islamic Fullday School.

Hasil observasi yang dilakukan peneliti, memperlihatkan bahwa guru IPA juga berbaur dengan guru yang lainya, saat jam istirahat di ruang guru. Hal ini membuat anggapan bahwa komunikasi guru IPA terbangung di sekolah dan tidak memiliki masalah berarti.

Kepala Sekolah juga mengungkapkan bahwa Guru IPA tercatat tidak pernah melakukan kesalahan atau kesalah pahaman yang serius dengan guru di sekolah ini. Semua berlangsung dengan baik, dan terkadang dalam suatu kondisi juga terlihat berbaur dengan guru yang ada.

Melalui hasil wawancara di atas, dapatlah dipahami bahwa Guru IPA menjalankan indikator kompetensi sosial dengan subindikator beradaptasi di tempat bertugas. Hal ini diperlihatkan dengan sikap membangun komunikasi yang baik dengan sesama guru di MIS Annur Islamic Fullday School, serta dapat berbaur dalam jam istirahat dengan guru yang lainnya.

\section{Berkomunikasi dengan komunitas profesi sendiri dan profesi lain secara lisan dan tulisan atau bentuk lain.}

Pendidik dirasa perlu untuk bergabung dengan komunitas profesi, dalam rangka meningkatkan kualitas pembelajaran yang diemban pada lembaga pendidikan tertentu. Dalam hal ini, Guru IPA diharapkan dapat berbaur dengan komunitas yang ada, untuk mencari dan mempelajari beragam hal postifi yang dapat diterapkan untuk meningkatkan kualtias pembelajaran.

Observasi yang dilakukan, membuat kesimulan bahwa guru IPA terlihat lebih banyak menghabiskan waktu di sekolah, tanpa bergabung dengan komunitas di waktu tertentu. Hal ini dilanjutkan dalam wawancara dengan Guru IPA yang mengatakan bahwa hingga kini belum 
tergabung dengan komunitas manapun tentang guru IPA. Jadi, setiap harinya hanya menghabiskan waktu untuk memberikan materi pelajaran kepada peserta didik di kelas.

Keadaan ini, juga diperjelas dengan hasil wawancara yang dilakukan kepada Kepala Sekolah, yang mengatakan bahwa memang guru IPA tidak bergabung dengan komunitas yang ada. Meski dipandang sebagai sesuatu yang baik, hingga kini belum ditemukannya jaringan atau wadah yang baik untuk itu. Informasi yang didapatkan tentang keberadaan komunitas itu, juga hingga kini belum didapatkan. Jadi, pada akhirnya guru IPA hanya mengajar di sekolah ini saja.

Komunitas juga tidak dapat dianggap sebagai sesuatu yang bernilai buruk. Sebab, melalui komunitaslah guru dapat bertemu dengan guru dari sekolah lainnya, dan memungkinkan untuk saling bertukar informasi, atau strategi mengajar yang mengarah lebih baik. Hal ini juga sejalan dengan hasil wawancara terhadap Guru Bidang Studi Matematika, yang mengatakan bahwa Guru IPA terlihat jarang berbaur di komunitas-komunitas tertentu, khususnya komunitas Guru IPA. Hingga kini, belum terdengar dalam lisan maupun tulisan tentang keikutsertaan guru IPA dalam komunitas tertentu yang mendukung profesinya.

Berdasarkan hasil wawancara dari berbagai informan penelitian, membuat anggapan bahwasanya guru IPA cenderung lebih banyak menghabiskan waktu untuk mengajar di kelas, dan terlihat belum bergabung dengan komunitas guru IPA dalam daerah kerjanya. Salah satu subindikator kompetensi sosial guru mata pelajaran, adalah komunikasi dengan komunitas, dan itu belum terlihat dicapai oleh guru IPA di MIS Annur Islamic Fullday School.

\section{SIMPULAN}

Kompetensi sosial adalah kemampuan guru sebagai bagian dari masyarakat untuk berkomunikasi dan bergaul secara efektif dengan peserta didik, sesama pendidik, tenaga kependidikan, orangtua/ wali peserta didik, dan masyarakat sekitar. Segala komponen pendidikan termasuk Guru, Peserta Didik, Orangtua siswa perlu membangun komunikasi aktif dan efisien diantara mereka, agar dapat menjalankan program pembelajaran dengan baik dan mencapai tujuan yang diinginkan.

Beberapa indikator kompetensi sosial telah dijalankan oleh Guru IPA di MIS Annur Islamic Fullday School. Namun, terdapat beberapa indikator yang belum sepenuhnya dillaksanakan oleh Guru IPA yang dimaksud. Adapun indikator yang dimaksudkan itu adalah berkomunikasi secara efektif, empatik, dan santun dengan orang tua dan masyarakat. Guru IPA dapat berkomunikasi dengan baik terhadap orangtua siswa. Namun itu hanya berlangsug tatkala ditemukan persoalan yang perlu diselesaikan, dan melalui panggilan telepon. Era modern, 
membuat komunikasi semestinya dapat terbantu dengan mudah dalam mencapai istilah efektif, yakni melalui WhatsApp Grup, dan guru IPA belum menerapkan hal ini. Secara umum, indikator berkomunikasi secara efektif dengan orangtua siswa.

Indikator lain yang belum sepenuhnya terpenuhi yakni berkomunikasi dengan komunitas profesi sendiri dan profesi lain secara lisan dan tulisan atau bentuk lain. Guru IPA berlum tergabung dengan komunitas tertentu terkait dengan bidang studi yang diembannya. Keadaan ini membuat guru IPA terlihat tidak memiliki waktu keluar dalam rangka pertemuan dengan komunitas tertentu. Komunitas adalah tempat yang tergolong positif, untuk dapat meningkatkan kualitas diri dengan mencari informasi dan mempelajari sesuatu yang baru dari teman komunitas.

\section{SARAN}

Adapun yang menjadi saran dalam penelitian ini yakni bagi peneliti selanjutnya, bahwa hasil penelitian ini dapat dijadikan sebagai bahan pertimbangan dan landasan untuk kelangsungan penelitian selanjutnya, serta dalam upaya memperdalam keilmuan tentang kompetensi sosial guru IPA.

\section{DAFTAR PUSTAKA}

Ali, \& Yusof, H. (2011). Quality and qualitative studies: The case of validity, reliability, and generalizability. 5 (1/2)(Social and Environmental Accounting), 25-26.

BSNP. (2006). Standar Isi Mata Pelajaran IPA SMP/MTs. Jakarta: BSNP.

Creswell, J. (2007). Qualitative Inquiry \& Research Design Choosing Among Five Approaches (2 ed.). California: Sage Publications.

Hasyim, A. (2016). Metode Penelitian Dan Pengembangan di Sekolah. Yogyakarta: Media Akademi.

Kurnia, H., Hasim, J., \& Samili, A. O. (2021). Peranan Kompetensi Guru Terhadap Pengembangan Life Skill Siswa SMP Negeri 31 Kabupaten Halmahera Barat. Jurnal Civic Education: Media Kajian Pancasila dan Kewarganegaraan, 5(2), 139-147.

Lestarai, I. (2018). Upaya Peningkatan Hasil Belajar IPA Melalui Metode Demonstrasi. Academy of Education Journal, 9(2), 95-100. https://doi.org/10.47200/aoej.v9i2.261

Luk Staff UGM. (2021). Perturan Pendidikan Nasional Republik Indonesia Nomor 16 Tahun 2007 Tentang Standar Kualifikasi Akademik dan Kompetensi Guru. Retrieved Desember 4, 2021, from Bahan Kuliah, Artikel, Tautan oleh Ir. Djoko Luknanto, M.Sc., Ph.D.: https://luk.staff.ugm.ac.id/atur/bsnp/Permendiknas16-2007KompetensiGuru.pdf

Marsiyah, M. (2016). PENINGKATAN HASIL BELAJAR SISWA KELAS VI PADA MATA PELAJARAN IPA TENTANG GERHANA BULAN DAN MATAHARI DENGAN MENGGUNAKAN METODE DEMONSTRASI DI SD NEGERI 1 KALIWANGI KECAMATAN PURWOJATI KABUPATEN BANYUMAS TAHUN PELAJARAN 
2015/ 2016. Academy of Education Journal, 7(1), 53-66. https://doi.org/10.47200/aoej.v7i1.350

Mulyasa, E. (2007). Standar Kompetensi dan Sertifikasi Guru. Bandung: PT. Remaja Rosdakarya.

Ngadinem, N. (2019). Penggunaan Media KIT IPA untuk Meningkatkan Kemampuan Siswa dalam Memahami Materi Gaya Magnet. Academy of Education Journal, 10(02), 152158. https://doi.org/10.47200/aoej.v10i02.280

Paiman, P. (2014). PERKEMBANGAN MORAL SISWA KELAS VI MADRASAH IBTIDAIYAH MA'ARIF SOKORINI KEC. MUNTILAN KAB. MAGELANG MENURUT TEORILAWRENCE KOHLBERG. Academy of Education Journal, 5(1). https://doi.org/10.47200/aoej.v5i1.108

Prasani, A., Herdiyanti, D., Puspita, L., \& Walid, A. (2021). EVALUASI PEMBELAJARAN DARING TERHADAP MATERI PEMBELAJARAN IPA KELAS IX SMPN 18 KOTA BENGKULU. Academy of Education Journal, 12(2), 246-253. https://doi.org/10.47200/aoej.v12i2.437

Sakina, N., Nurmawati, S., Sarawati, Y., \& Walid, A. (2021). EVALUASI PEMBELAJARAN DARING TERHADAP MATA KULIAH STATISTIKA IPA IAIN BENGKULU. Academy of Education Journal, 12(1), 149-157. https://doi.org/10.47200/aoej.v12i1.436

Sudrajat, Y. (2020). IMPLEMENTASI PEMBELAJARAN AKTIF (ACTIVE LEARNING) UNTUK MENINGKATKAN KOMPETENSI SPIRITUAL DAN SOSIAL SISWA DALAM PEMBELAJARAN PENDIDIKAN PANCASILA. Academy of Education Journal, 11(2), 142-167. https://doi.org/10.47200/aoej.v11i2.398

Suhana, Nanang Hanafiah, \& Cucu. (2012). Konsep Strategi Pembelajaran. Bandung: Refika Aditama.

Suryabrata, S. (2013). Metodologi Penelitian. Jakarta: Rajawali Pers.

Suryana. (2010). Metodologi Penelitian: Model Praktis Penelitian Kualitatif dan Kuantitatif. Universitas Pendidikan Indonesia.

Taonah, T. (2016). PENGUNAAN METODE PICTURE AND PICTURE UNTUK MENINGKATKAN PRESTASI BELAJAR SISWA PADA MATERI PENGGOLONGAN HEWAN BERDASARKAN JENIS MAKANAN MATA PELAJARAN IPA KELAS IV SD NEGERI 3 PURWOJATI SEMESTER I TAHUN PEAJARAN 2015/ 2016. Academy of Education Journal, 7(1), 36-44. https://doi.org/10.47200/aoej.v7i1.348

Wibowo, A., \& Hamrin. (2012). Menjadi Guru Berkarakter. Yogyakarta: Pustaka Belajar.

Yumarlin, M. (2013, April). Pengembangan Permainan Ular Tangga untuk Kuis Mata Pelajaran Sains Sekolah Dasar. Jurnal Teknik, 3, 1. Dipetik Desember 2021, dari https://www.researchgate.net/publication/319416534_PENGEMBANGAN_PERMAI NAN_ULAR_TANGGA_UNTUK_KUIS_MATA_PELAJARAN_SAINS_SEKOLA H_DASAR 